\title{
Muerte súbita cardíaca en un paciente esquizofrénico: ruptura de la pared libre del ventrículo izquierdo por infarto agudo de miocardio. Exposición de un caso y revisión de la literatura.
}

Sudden cardiac death in schizophrenic patient: left ventricular free wall rupture due to acute myocardial infarction. Case report and literature review.

A. Rico y cols.

Cuad Med Forense 2002;30:51-59

Se trata de un varón, de 3 I años de edad, diagnosticado de esquizofrenia paranoide, en tratamiento con Olanzapina (Zyprexaß), e historia de varios ingresos hospitalarios por ingesta medicamentosa. Fue hallado muerto en la cama por los familiares que referían que durante las 24 horas anteriores se había quejado de molestias retroesternales que fueron consideradas como secundarias a su proceso psiquiátrico por lo que no se solicitó asistencia médica. El cadáver mide $170 \mathrm{~cm}$ y tiene un peso estimado de $65-70$ kg. Tras la apertura del tórax encontramos el pericardio a tensión que traslucía una coloración negruzca; una vez abierto se observaron coágulos sanguíneos que daban lugar a taponamiento cardíaco (Figura $\mathrm{n}^{\circ} \mathrm{I}$ ).

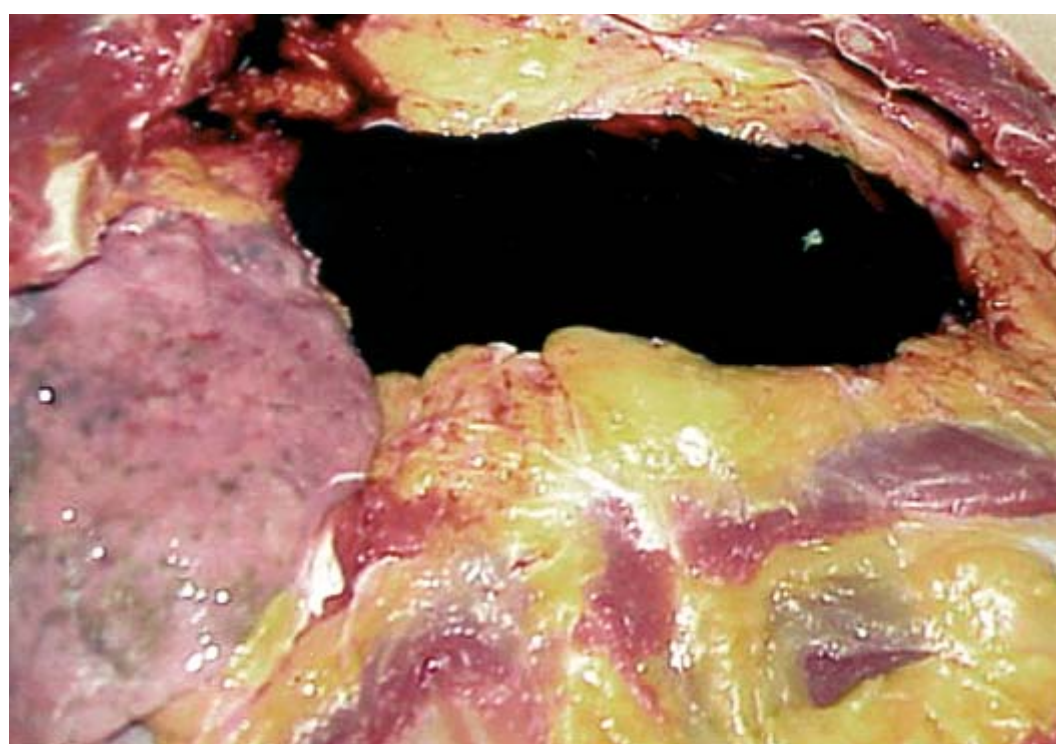

Figura 1.- Taponamiento cardíaco. 
El corazón pesaba 450 gramos, con abundante grasa epicárdica, presentando en la cara anterior del ventrículo izquierdo un desgarro en su pared, perpendicular al eje longitudinal, transmural, de 2,5 cm de longitud, a $4 \mathrm{~cm}$ del ápex cardíaco (Figura $\mathrm{n}^{\circ} 2$ ). Dicha rotura de la pared presentaba un infiltrado hemático perilesional, de $4 \mathrm{~cm}$ de diámetro que se correspondía con un infarto agudo de miocardio en el territorio de la arteria coronaria descendente anterior (Figura $n^{\circ} 3$ ). El análisis toxicológico de la sangre fue negativo y el estudio histotopatológico del corazón puso de manifiesto: Rotura ventricular izquierda, perforante, post-infarto de miocardio. Trombosis de la arteria coronaria descendente anterior debida a rotura de placa de ateroma infectada. Arteritis coronaria.

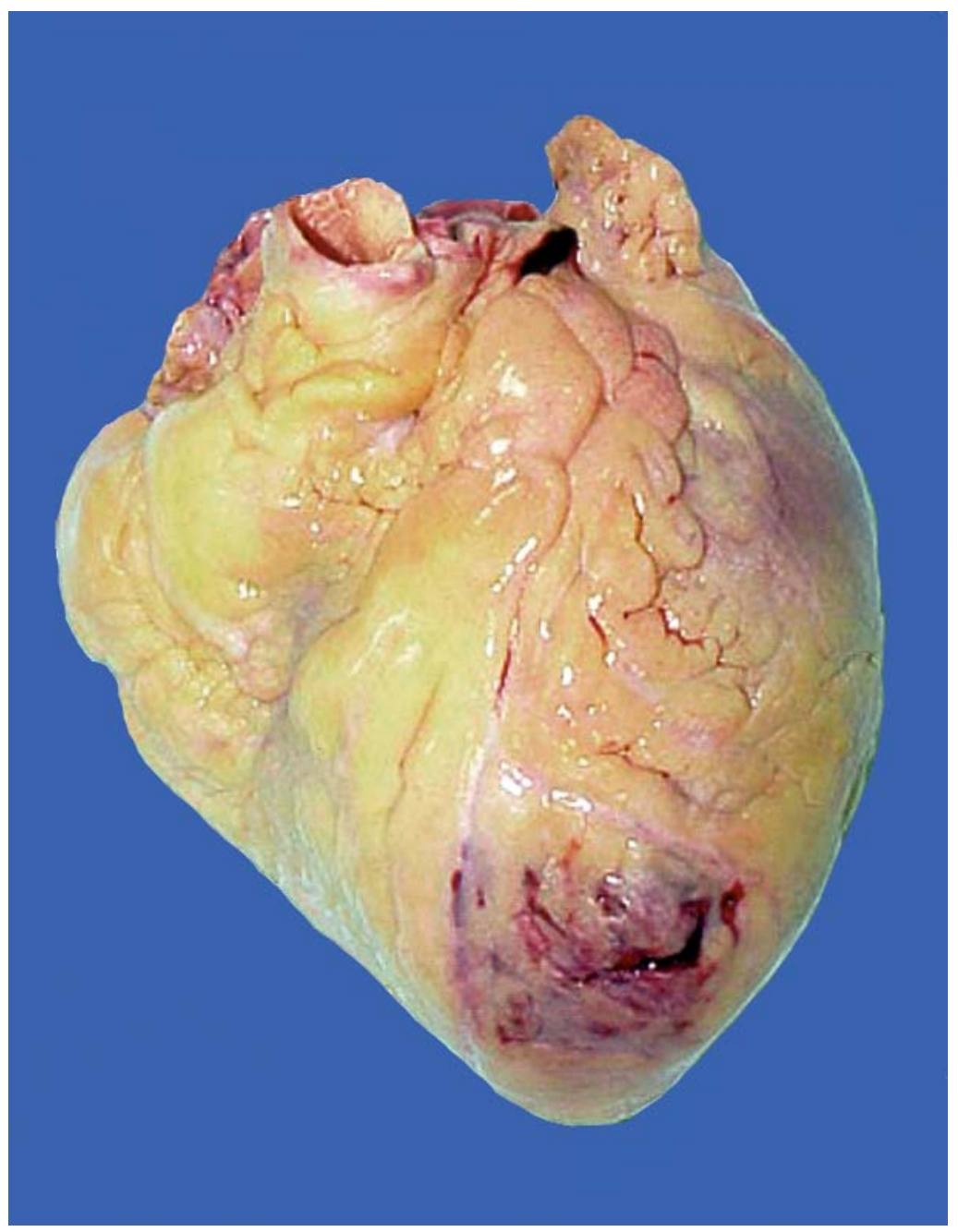

Figura 2.- Ruptura cardiaca. 


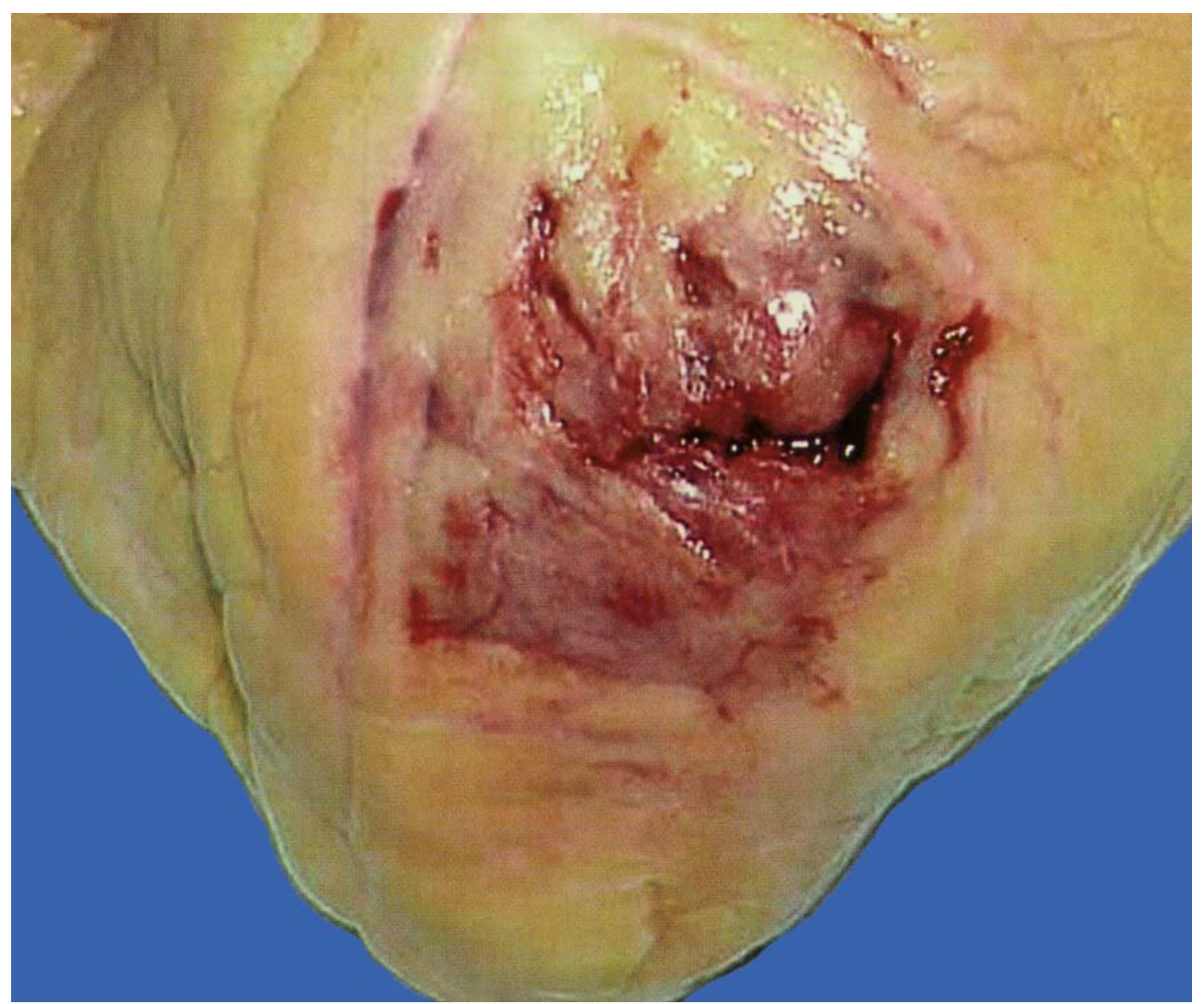

Figura 3.- Zona de infarto con ruptura de la pared libre ventricular. 